\title{
The Modernization of the Chinese
}

\section{Salt Administration, 1900-1920}

Harvard East Asian Series 53

The East Asian Research Center at Harvard University administers research projects designed to further scholarly understanding of China, Japan, Korea, Vietnam, and adjacent areas. 




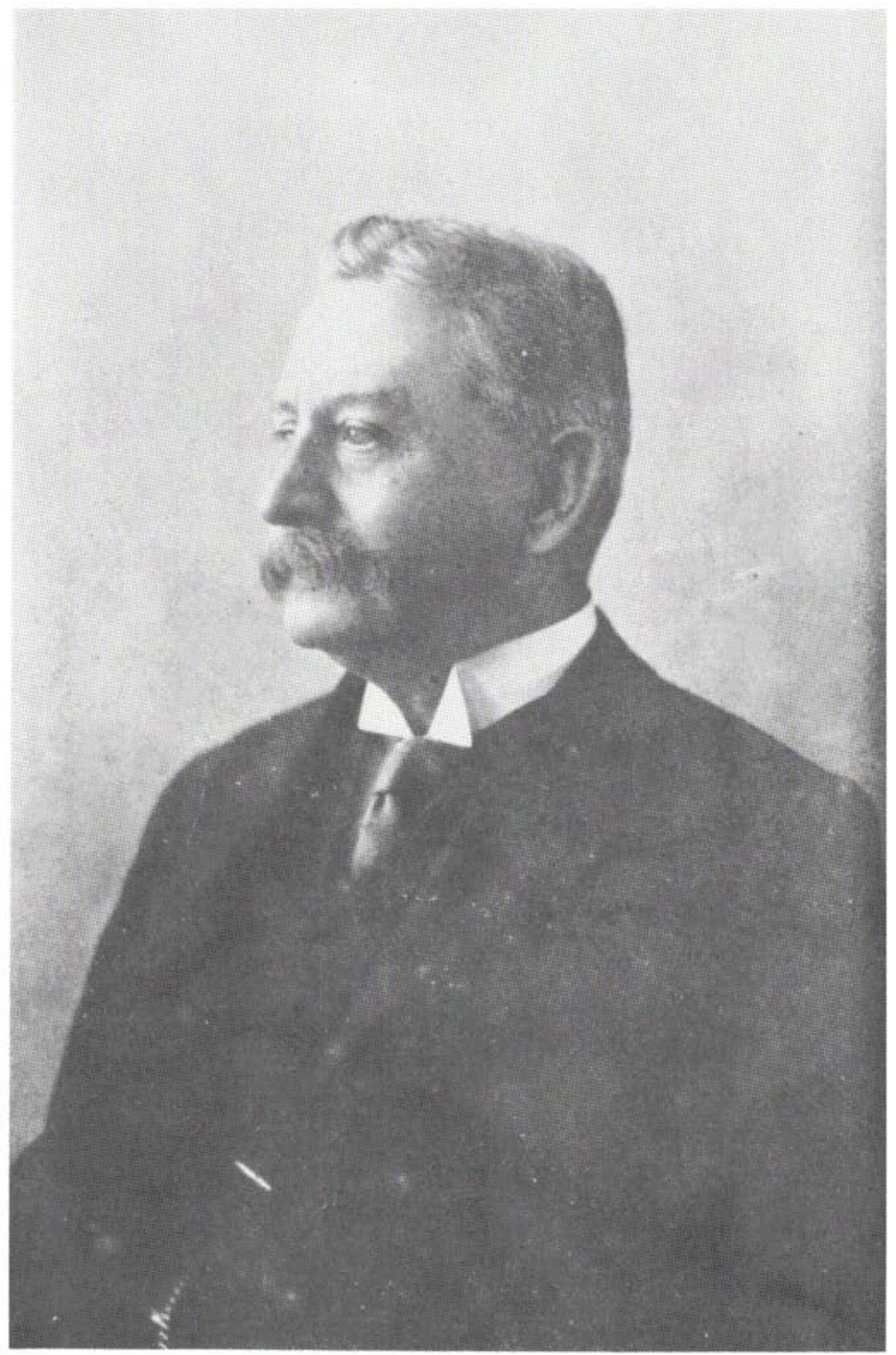

Sir Richard Dane 


\title{
The Modernization of the Chinese Salt Administration, 1900-1920
}

\author{
S. A. M. Adshead
}

Harvard University Press

Cambridge, Massachusetts

1970 
(C) Copyright 1970 by the President and Fellows of Harvard College All rights reserved

Distributed in Great Britain by Oxford University Press, London

Preparation of this volume has been aided by a grant from the Ford Foundation

Library of Congress Catalog Card Number 77-120315

SBN 674-58060-5

Printed in the United States of America 
In Memory of

James Miller Vine

Carissimus Socer 
